\title{
PREVELANCE AND RISK FACTORS OF RECURRENT DIABETIC KETOACIDOSIS IN ADULT TYPE 1 DIABETIC PATIENTS
}

Talaat Abdelfatah Abdel Atty, Reem Mahmoud Fathalla, Asmaa Abdelshafy Elsharnouby Mohamed

Department of Internal Medicine, Faculty of Medicine, University of Alexandria, Resident at Ministry of Health

\section{Introduction}

- Diabetic ketoacidosis is an acute life-threatening complication of diabetes. DKA is defined clinically as an acute state of severe uncontrolled diabetes associated with ketoacidosis that requires emergency treatment with insulin and intravenous fluids. DKA accounts for $14 \%$ of all hospital admissions of patients with diabetes and $16 \%$ of all diabetes-related fatalities.

Almost 50\% of diabetes-related admissions in young persons are related to DKA.

- The overall mortality rate for DKA is $0.2-2 \%$, with persons at the highest end of the range residing in developing countries.

Research shows that recurrent diabetic ketoacidosis rates are dependent on medical services and socioeconomic circumstances of the adolescents.

- Incidence of recurrent DKA varies across different countries, with a recent
sentices and socioeconomic circumstances of the adolescents. Incidence of recurrent DKA varies across different countries, with a recent
systematic review in adult populations with Type 1 diabetes indicating a range between $8-56$ persons per 1000 years.

\section{Airn of the work}

- Evaluate the prevalence and risk factors for recurrence of DKA in adult patient with type 1 diabetes presenting to DKA critical care unit of diabetes and metabolism unit in Alexandria Main University Hospital.

\section{Patilents and Mithods}

Patients: This cross sectional study was conducted over the period of 9 months. Patients included in the study were recruited from DKA critical care unit of diabetes and metabolism unit, internal medicine department in Alexandria Main University hospital

Methods: All the included patients was subjected to:

1 - full history and physical examination

2- full lab investigations were done including $\mathrm{Hb} \mathrm{Alc}$

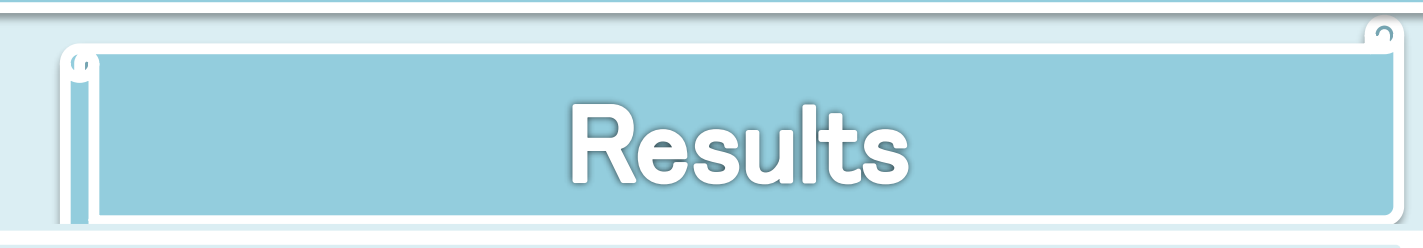

Table : Distribution of the studied cases according to different studied parameters

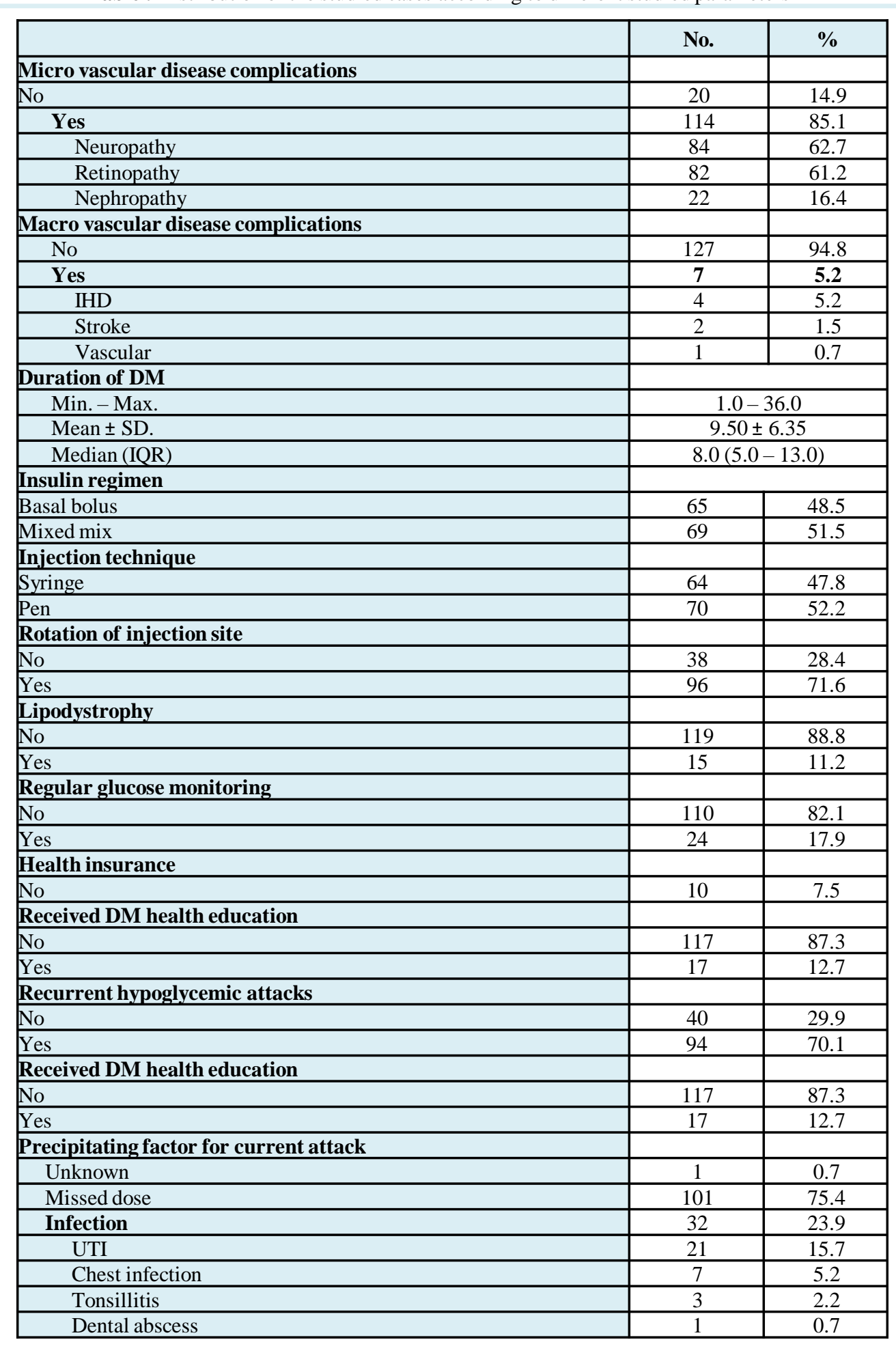

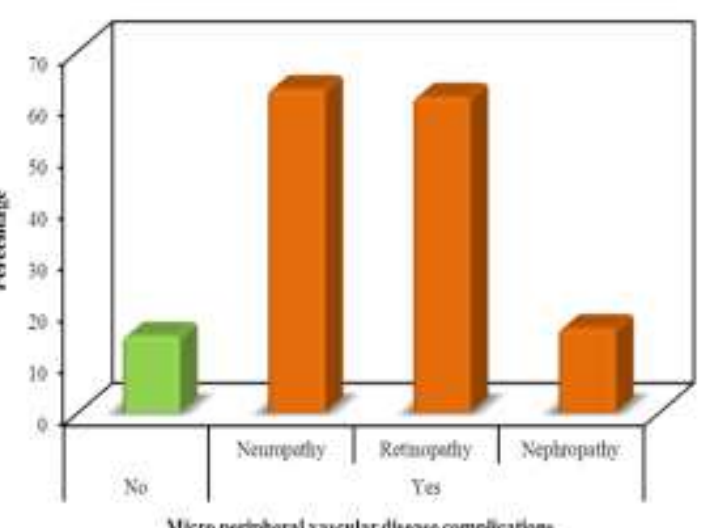
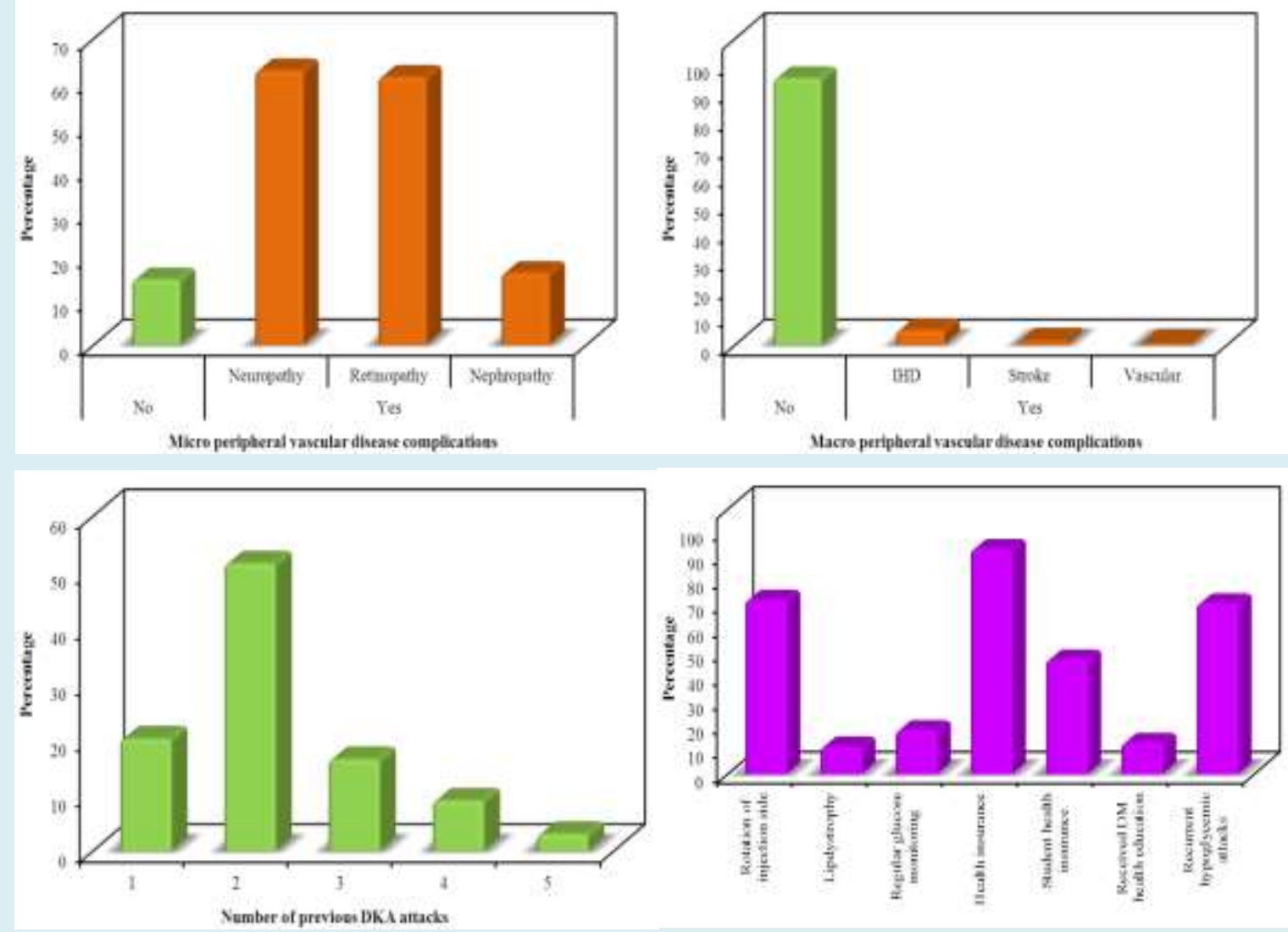

Figure: Distribution of the studied cases according to different studied parameters

\section{Gonelusion}

- Omission of insulin dose is a major risk factor for recurrence of DKA, recurrent hypoglycemic attacks. The main risk factors for DKA recurrence are lack of health education and noncompliance on regular glucose monitoring.HbAlc levels are positively

$$
\begin{gathered}
\text { 20210Alexandria Faculty of Medicine } \\
\text { CC-BY-NC }
\end{gathered}
$$

MEDICINE $\mid$ Pry 